\title{
Variations in how Students describe 'Friendship' An Application of Appraisal Theory
}

\author{
Mohammed Alhuthali* \\ Foreign Langauges Department, Faculty of Arts, Taif University, Taif 21944, Saudi Arabia \\ Corresponding Author: Mohammed Alhuthali, E-mail: mohammed.alhuthali@gmail.com
}

\section{ARTICLE INFO}

Article history

Received: June 16, 2018

Accepted: August 08, 2018

Published: November 01, 2018

Volume: 7 Issue: 6

Advance access: September 2018

Conflicts of interest: None

Funding: None

\begin{abstract}
This study explores the link between cognition and emotion using concepts from functional linguistics. Appraisal Theory argues that all emotions are first articulated (actively or passively) before they are experienced. As with many essentially constructionist approaches, this process is influenced both by circumstances and previous experience. This study specifically tests if positive and negative framings of the concept of friendship use different linguistic formulations. If so, this provides some evidence both for the underlying theoretical assumption and the value of functional linguistics as a tool to understand the process. Appraisal Theory has roots in both Psychology and Functional Linguistics and this study aims to bring these two strands together so as to link the analytic framework from Functional Linguistics to the conceptual framework in the Psychological formulation. In conclusion, it was found that negative formulations used more complex language, offered alternative formulations and used words to indicate both the focus and to modulate the force of any statement. In the context of the study, it was suggested that positive images of friendship reflected their expectations of the behaviour of close family members.
\end{abstract}

Key words: Appraisal Theory, Functional Linguistics, Friendship

\section{INTRODUCTION}

Appraisal Theory has roots in both Psychology and Functional Linguistics. In its Psychological aspect (Lazarus, 1993), the key element is to argue that emotions must first be structured as a cognition (even if this is largely automatic) and then expressed as an emotion. However, one enduring issue with such constructivist approaches is to find a means to capture and reflect the process being used. In this respect, Appraisal Theory in Functional Linguistics (Martin and White, 2005) is helpful as it seeks to break down the various semiotic tools used to reflect emotion in either speech or text.

Appraisal Theory (Lazarus, 1993) was an attempt to link how emotions are experienced to the underlying cognitive process. In particular the cognitive element includes both the interpretation of an event and an attempt to formulate a suitable response (Lazarus, 1991). This interaction can be all but automatic using pre-learnt scripts and frames (Augoustinos et al., 2014; Gratch and Marsella, 2005; Lories et al., 1998) or be a consequence of active thinking and testing of possible explanations and responses.

As such, Appraisal Theory seeks to understand both how individuals describe emotions and how others interpret any display of emotion. This created (Roseman and Smith, 2001) a key assumption is of consistency in that the attribution of a given emotion depends on how it is appraised but is also done consistently when the same criteria are present. In ef- fect, if someone ascribes a particular emotion to a particular event then this should be consistent assuming no change in external circumstances. Equally, this assumes that the act of appraisal, even if not really articulated as an active cognitive process, is a precondition for the subsequent emotional description (in effect, that emotions come from cognition rather than are an independent psychological state).

Functional Linguistics (Halliday, 1978; van Leeuwen, 2006) can be useful in understanding this process of understanding and interpretation as it starts from an exploration of how meaning is both constructed and interpreted (Berger, 1994). Within this process Halliday (1978), in particular, added the argument that the social environment and norms informed the process of meaning making as much as the linguistic structure of a text shifting the focus just from the use of language to capture a social aspect to meaning making. This means that to understand the intention in text there is a related need to understand the context both in which the text was generated and in which the text is interpreted.

However, emotions are particularly difficult to capture using the concepts of linguistics as they are subject to interpretation both by the active participant and any one observing or reading the resulting formulation. A solution, using a form of Appraisal Theory (Martin and White, 2005), is to argue that the patterns of language reflect both the writer's understanding of an emotion (or emotional state) and, to a lesser extent, how the reader might interpret such statements. To make this 
bridge means using a conceptual framework which captures how the representational and textual elements of a written description interact (Martin and White, 2005).

However, this can be particularly challenging when text in question is a reflection of an emotional value, in this case, of the value to be placed on friendship. To address this, the purpose of the study was to understand how students made their evaluation and appraisal of the concept. The students in this study were all male and taking a module designed to improve their written English at a university in Saudi Arabia and were aged between 19 and 21. In total, 55 students were taking the modules and the assignments of 51 students were analysed (those excluded were deemed too poor in their usage of English to be of value). The students were aware that their assignments would be used for research purposes and gave their consent.

This creates several interesting aspects to this study. The students are using a second language and this might be expected to alter how they articulate their emotional understanding. In particular, whether the richer description of friendship by some students flows from emotional maturity or is simply a product of their greater command of English as a Second Language. Equally, they are can be expected to frame friendship using the norms of Saudi society rather than those prevalent in other countries. Against, this framework, this study seeks to understand if the language is different between positive and negative emotions and how far the students' presentation of the concept of friendship can be understood in terms of their own backgrounds and experiences.

\section{LITERATURE REVIEW}

As noted in the introduction, Appraisal Theory has taken on slightly different forms within Psychology and Functional Linguistics. However, it is useful to understand how they share some key concepts as this strengthens both an understanding of the underlying theory and of any analytic framework.

\section{Appraisal Theory in Psychology}

In its Psychological format, Appraisal Theory is an attempt to understand how emotions arise first as cognitions (even if this is not active but reactive or simply using pre-learned behaviour) and how this leads to the emotional state. This framework has led to several ongoing debates (Lazarus, 1993) with some approaches coming close to classic Behavioural Psychology (and thus underplaying the importance of cognition) with a focus on the observed emotion and others strongly suggesting that emotion can only be effectively studied from a constructionist perspective (McEachrane, 2009). This constructionist approach has come to dominate (Smith et al., 2014) with both how emotions are described and perceived being derived from the situation, background of the individual(s) and the varying linguistic and non-verbal grammars available (Ellsworth, 2013). In effect, emotions can be described both as processes (the move from event to cognition to emotion) and as adaptive responses involving both personal and environmental aspects (Moors et al.,
2013) affecting both the active individual and the interpretation by others.

One way to address this complication is to adopt the subject-object concept common in many modernist theories (Christopher et al., 2012) in applying appraisal theory. In this, a key distinction is made between the object (emotion) being described and the language available to actually describe it. The latter is seen to be subjective and constructed but the former has a more concrete state (Bem and Looren de Jong, 2006).

Lazarus' original formulation (Lazarus, 1991) stressed how the understanding of a situation determined how an individual reacted. He argued that this process used two major types of appraisal methods: 1) primary appraisal, where an individual tries to interpret an event; and, 2) secondary appraisal, where they try to understand the implications. Since Lazarus was primarily interested in stress, his argument was that stress (as an emotion) arose from this process of interpretation and understanding. This model was subsequently expanded to create a two process model of appraisal-response-re-appraisal (Smith and Kirby, 2001). In turn, differences have been drawn between appraisal using pre-learned schemas or conscious cognition (Gratch and Marsella, 2005).

\section{Appraisal Theory in Functional Linguistics}

Many of these ideas re-appear within the wider literature on social semiotics. How we interpret and present emotions can be verbal or non-verbal (Williamson, 2005) with this often involving multimodal (speech and gesture or facial expression) interactions to represent our feelings and, in turn, influencing how others interpret these messages (Kress, 2010). In the case of a written statement, it is only feasible to concentrate on the presented text both as a tool of expression and as the evidence a reader will use to evaluate that meaning. In this respect, Appraisal Theory (Martin and White, 2005) can be used to create a taxonomy with three main elements. This is set out below:

In this structure, Attitude is used to capture those elements in the language that are used by the reader to identify issues such as personal feelings and values. The sub-division of Affect captures the understanding of the emotions embedded in the text, Judgement reflects how the text indicates assessment of the character and behaviour of others and Appreciation relates to judgements of the value of specific things. Most often this aspect is socially determined as both writer and reader will draw on the context (either within the text or in wider society) in order to judge how appropriate something is. In this respect, judgement, in particular, is socially determined, both in the terms of the original author and of any subsequent reader (Coffin, 2003).

Engagement is used to reflect the degree of nuance in the statements. Thus the more categorical the writing is seen to be more, the more likely it will be described as Monogloss. If the writing allows for multiple meanings or is used to contrast different concepts then it can be described as Heterogloss.

Graduation, in turn, is used to capture instances where the language is structured to either emphasise a particular 
point or to focus on an particular aspect. Thus a neutral statement, indicating either lack of understanding or focus, will lack both aspects. As with the other categories it is also possible for any statement to have more than one aspect so a statement could stress both the focus and moderate the force if this was appropriate.

\section{STUDY DESIGN}

Since the focus of this study is an evaluation of written statements, a framework such as Martin and White's (2005) is appropriate. Any evaluation can only use the available text so there is no need to adopt a more complex multi-modal analytic structure. As noted in the introduction the responses of 51 out of a group of 55 students were used. Those discarded were too poor to allow for any structured analysis of how the student was representing the concept of friendship.

The data was coded using the taxonomy set out in Figure 1. Each phrase that described their emotional understanding of the concept of friendship was coded. This allowed a focus on the key concepts in the written responses rather than cover the entirety of their description. This meant it was possible both to identify patterns in the language used to express friendship and see if there were any differences between positive and negative framings. Some phrases were given multiple codings as they met the characteristics of more than one category. The exception in this regard was to treat the difference between Monogloss and Heterogloss phrases as exclusive so that a phrase either was coded to one or the other or left blank against this category.

The result was to identify 197 phrases (so an average of just under 4 per person). Some of the responses were very short and only contained two separate ideas (this applied to 8 responses) while others showed substantial subtlety in their presentation and produced six separate ideas (this applied to six responses).

\section{Single Data Coding}

The first task was to code each response as to whether it contained a positive or negative framing of the concept of friendship. 165 responses were coded as positive and this ranged from how they identified the gains of friendship ('help you when you need help') or how they saw it emotionally ('friends is a beautiful thing'). Negative codings could be sub-divided into two concepts. The main issue was an identification by a number of the students of the problems that can arise from having bad friends [' bad friendships they will destroy your life') but was also used when they identified friendship with negative emotions ('to be sad when he is sad'). In combination, this created 32 negative statements.

Within the wider concept of Attitude, Affect was identified from phrases such as 'like a brother' or 'friendship is beautiful in life'. This produced 42 individual phrases. Judgement was more common (135 phrases) and reflected comments such as 'friend is like having a brother' and 'you

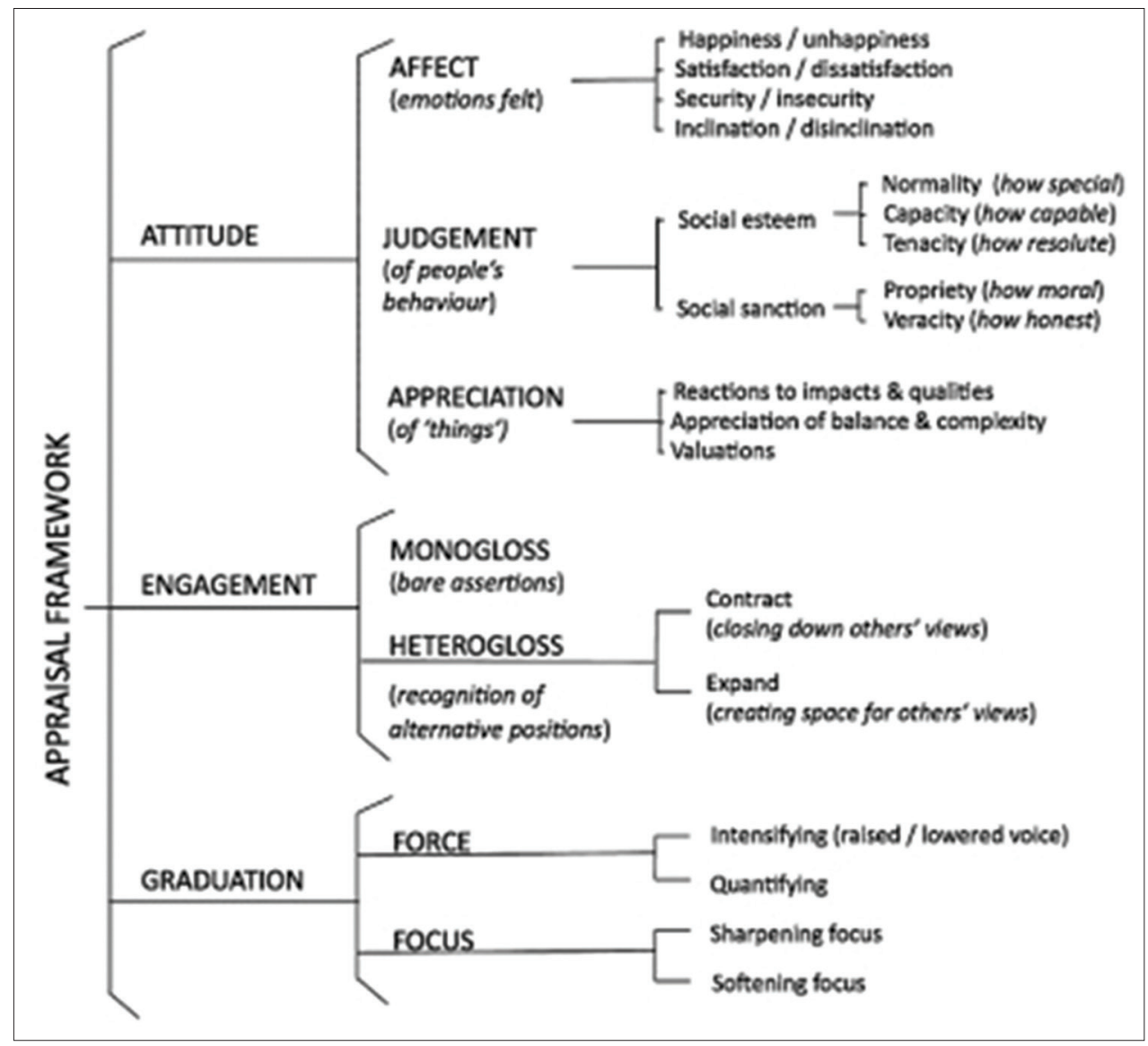

Figure 1. Outline of an appraisal framework (Martin and White, 2005) 
support him'. Appreciation was less commonly expressed (62 phrases) and was reflected in phrases such as 'hold each other and comfort each other' and 'rely in a very critical situation'.

As noted above, the distinction between Monogloss and Heterogloss was mutually exclusive. The latter was indicated by phrasing such as 'first, friendship is something very wonderful'. Monogloss was used when the presentation of friendship allowed for no alternative interpretation. In effect, the student set out a single framing of the concept with no nuance or comparisons.

In terms of Graduation, Force (68 instances) was used less often than Focus (130 instances). Typical of the instances coded as Force were 'drag you to the bottom' and 'one of the most important relationships' while Focus was captured by phrases such as 'I think you should be aware of bad friends' and 'treat as your brother'.

\section{Multiple Coding}

As identified above, many phrases were coded against multiple categories. As an example 'you must choosing a good person' was coded as an example of judgement, Monogloss and with both force and focus. If the coding between Monogloss and Heterogloss is ignored, only 28 phrases had a single code attributed to them. Common combinations were for a phrase to indicate both judgement and focus as: 'friendship are very important in life' (in this respect it is worth noting that any mistakes in the original English have been retained in this analysis).

\section{FINDINGS}

This section applies the framework of Martin and White (2005) to the student essays. The coding structure above was used and the first stage is to report on the findings under each of the main headings.

\section{Attitude}

Table 1 below shows the number of responses in terms of attitude and the spread between positive and negative responses.

As discussed above, the majority of the statements of attitude can be seen to fall into the format of judgements. Commonly this was about the nature of friendship or the ways in which it was expected that friends would treat each other. Of note, the highest proportion of negative statements were couched in terms of judgements. As mentioned in the coding discussion, the negative framing was used when friendship was posed as creating problems - either in terms of demands or, quite commonly, of fear of being misled.

Examples of where friendship can be seen as placing demands include 'to be sad when he is sad' and 'not just for fun and easy times'. This formulation was relatively common and could be seen as acknowledging that friendship brought both benefits and responsibilities. Equally the negative consequences of having no friends were captured
Table 1: Attitude

\begin{tabular}{l|c|c|c|}
\hline Type & Affect & Judgement & Appreciation \\
\hline Negative & 6 & 27 & 10 \\
\hline Positive & 36 & 108 & 52 \\
\hline Total & $\mathbf{4 2}$ & $\mathbf{1 3 5}$ & $\mathbf{6 2}$ \\
\hline \% Negative & $14.29 \%$ & $20.00 \%$ & $16.13 \%$ \\
\hline
\end{tabular}

by phrases such as 'life without friends nothing at all'. Some students made clear judgements of the problems that can arise from poorly chosen friends as 'bad friendship ... stay away from', 'I think you should be aware of bad friends'. Only one student essentially offered nothing but negative statements in terms of their attitude towards the concept of friendship. In effect, many of those who offered up a negative judgement balanced this with a more positive statement.

\section{Engagement}

As indicated in the coding discussion, the great majority of statements were coded as Monogloss.

Before looking at the reasons for that (Table 2), it is worth noting that of the few heterogloss statements, a relatively high proportion came from negative framings of friendship. One reason for this is the extent that most of those students who did offer a negative frame also did so in a relatively balanced way. In effect they presented friendship as a relatively complex structure and also each of these statements was also coded as a judgement in terms of attitudes. The six negative, heterogloss statements were:

- bad friendship ... stay away from

- friend to good people and stay away from bad people

- life without friendship is very hard

- not just good but bad things

- not just for fun and easy times

- bad friendships they will destroy your life

Beyond this it is clear the great majority of statements were straightforward assertions of what the student believed friendship to be about. Common issues were to link being a friend to that of a close family member ('like a brother' was used very often). Other common formulations were about the role of a friend ('he depends on you'). This dominance might be for one of several reasons.

First, the students were writing in a second language and relatively simple sentence structures are much easier to use than when usage is made of subordinate clauses. However, while likely to explain some of the difference, this is not likely to be the dominant explanation. Partly as the coding was at the level of phrase or group of words and the need to keep to simple sentences did not stop some students using formulations such as 'many meanings' or 'different from one to another' when describing the value of friendship. A secondary explanation could be that the students were reflecting Saudi social norms in their answers. The dominant single framing of friendship was as a relationship akin to that between family members but this was offset by a frequent expectation of a friend being someone who 'must keep these secrets'. Given that Saudi society tends 
Table 2: Engagement

\begin{tabular}{l|c|c|}
\hline Type & Monogloss & Heterogloss \\
\hline Negative & 25 & 6 \\
\hline Positive & 139 & 23 \\
\hline Total & 164 & 29 \\
\hline$\%$ Negative & $15.24 \%$ & $20.69 \%$ \\
\hline
\end{tabular}

Table 3: Graduation

\begin{tabular}{|c|c|c|}
\hline Type & Force & Focus \\
\hline Negative & 14 & 27 \\
\hline Positive & 54 & 103 \\
\hline Total & 68 & 130 \\
\hline$\%$ Negative & $20.59 \%$ & $20.77 \%$ \\
\hline
\end{tabular}

to emphasise links within kinship groups (Achoui, 2006; Long, 2005), it is perhaps to be expected that other successful personal relationships are framed as being akin to those within a family. In effect, the students expect successful friendships to be akin to the relations they have within their family group.

\section{Graduation}

Within the framework of Appraisal Theory, Graduation identifies when a statement is modified to either indicate the focus to which it applies or the strength to which it is important.

In this case, it is clear that negative statements about friendship were more often modified either by intensity or focus. In effect as shown in Table 3, both formulations were used more often for negative statements than for positive statements. This may reflect the indication above that negative statements were more likely to made up of a complex argument with a nuanced presentation.

However, it is clear that students tended to indicate the focus of their statement far more often than they modified the force. The former was relatively common and ranged from 'know what things make him glad or sad' to 'friendship is beautiful in life'.

In this respect, competence in using a language may play a role. In effect it is easier to construct a phrase that indicates the focus than it is to insert a modifying adjective or adverb to alter the force. However, as with the discussion about the dominance of monogloss statements, this again may reflect Saudi norms. In effect the students find it more appropriate to state what friendship is about rather than need to modify their statements.

\section{DISCUSSION}

What is clear is that negative framings of the concept of friendship are more complex than the positive ones. However, while this is clear in that the use of heterogloss formulations is more common for when discussing negative emotions, in other respects there are no clear correlations between complexity and the emotions reported. In terms of attitude, negative statements are less likely to be in terms of affect (i.e. of the emotions felt) and far more likely to be judgemental (and there is no difference in terms of appreciation). This may support an argument that in doing so, the students are drawing on cultural norms and expectations and using these to frame their judgement about the role of friendship in their lives.

The findings around appreciation may relate to the lack of focus on things (i.e. attributes of a friendship). In effect, when identifying negative responses, the students tended to frame this in terms of judgement, mainly capturing the ways in which a bad friendship (or a demanding one) can manifest itself. Of note, negative statements are also more likely to show graduation with little change as to shift in force or focus. This again may reflect the extent that the students felt it necessary to be more clear about the circumstances that created a negative emotion in terms of friendship.

On the other hand, positive statements tended to relatively simple (monogloss) and directly capture emotion (affect) often in terms of the perceived emotional benefit of friendship.

Overall the responses tended to be monogloss, reflect judgements and to use graduations in terms of force. This may be a product of either the students' competence in using English with a tendency towards simple formulations and direct description but also may reflect aspects of their own cultural background. In effect, this type of framing of friendship reflects what they have learnt to expect. In this respect, it is worth stressing that the single most common formulation of the role of a friend is as akin to a brother or other close family member. This may reflect both the available reference frame and the type of engagement they are seeking from non-family friends.

\section{CONCLUSIONS}

Appraisal Theory argues that emotions are preceded by some form of cognition reflecting the process of interpreting information, relating this to previous experiences and social expectations. When used in the context of functional linguistics (Martin and White, 2005), the focus is more on how language is used to reflect this construction of meaning. However, one challenge is to ensure that the link back to the underlying psychology is retained in any analysis. In effect, the original theoretical structure (Lazarus, 1991; Lazarus, 1993) argues that a precondition to feeling an emotion is the ability to construct a cognitive model (McEachrane, 2009).

In practice many studies either use the psychological aspects of the theory (usually applied to how individuals experience emotions such as stress) or use the semiotic aspects. This paper suggests that deeper insights can be derived when the two perspectives are combined.

In the case of this research, the students were asked to write a short essay setting out their understanding of friendship using a second language (which some of them were learning for the first time). As such, there may well have been a bias towards using simple phrases and relying on standard concepts (such as the idea of a friend being like a 
brother) rather than setting out detailed, or subtle, explanations. This cultural background may explain the overall bias towards a formulation that tended to stress judgements, be monogloss and emphasise the focus of their understanding. However, this is not a sufficient explanation for the reasons why negative statements about friendship tended to be more complex than positive statements.

This suggests that the positive and negative emotional framing of friendship do derive from different cognitive structures and certainly are expressed in different language. In particular, it would appear that to express a negative emotion requires more nuance than a positive one does.

The findings in this paper could be extended by shifting the focus from a description of an interpersonal relationship to one that required a focus directly on an emotional state. However, it strongly supports an overall approach that seeks to combine the psychological and linguistic aspects of Appraisal Theory as a valuable means to explore the process of meaning making.

\section{REFERENCES}

Achoui, M. M. (2006). The Saudi society: Tradition and change. In: Georgas, J., Berry, J. W., Vijver, F. J. R. V. D., Kagitcibasi, C. \& Poortinga, Y. H. (eds.) Families across cultures: A 30-nation psychological study. Cambridge: Cambridge University Press.

Augoustinos, M., Walker, I. \& Donaghue, N. (2014). Social Cognition: An Integrated Introduction, $3^{\text {rd }}$, London, Sage

Bem, S. \& Looren de Jong, H. (2006). Theoretical Issues in Psychology, 2nd ${ }^{\text {nd }}$ London, Sage

Berger, A. A. (1994). Cultural criticism: a primer of key concepts, London, Sage

Christopher, S. G. K., Armineh, N. \& Jin-Cheon, N. (2012). Sentiment analysis of online news text: a case study of appraisal theory. Online Information Review, 36:6, 858-878.

Coffin, C. (2003). Exploring different dimensions of language use. ELT Journal, 5711-18.

Ellsworth, P. C. (2013). Appraisal Theory: Old and New Questions. Emotion Review, 5:2, 125-131.

Gratch, J. \& Marsella, S. (2005). Evaluating a computational model of emotion. Autonomous Agents and Multi-Agent Systems, 11:1, 23-43.

Halliday, M. A. K. (1978). Language as Social Semiotic: The Social Interpretation of Language and Meaning, London, Edward Arnold
Kress, G. (2010). Multimodality: A social semiotic approach to contemporary communication, London, Routledge

Lazarus, R. S. (1991). Progress on a cognitive-motivational-relational theory of emotion. American psychologist, 46:8, 819-834.

Lazarus, R. S. (1993). From Psychological Stress to the Emotions: A History of Changing Outlooks Annual Review of Psychology, 441-21.

Long, D. (2005). Culture and Customs of Saudi Arabia, Greenwood Publishing Group

Lories, G., Dardenne, B. \& Yzerbyt, V. Y. (1998). From Social Cognition to Metacognition. In: Yzerbyt, V. Y., Dardenne, B. \& Lories, G. (eds.) Metacognition: Cognitive and Social Dimensions. London: Sage.

Martin, J. R. \& White, P. R. R. (2005). The Language of Evaluation: Appraisal in English, Basingstoke, England, Palgrave Macmillan

McEachrane, M. (2009). Emotion, Meaning, and Appraisal Theory. Theory \& Psychology, 19:1, 33-53.

Moors, A., Ellsworth, P. C., Scherer, K. R. \& Frijda, N. H. (2013). Appraisal Theories of Emotion: State of the Art and Future Development. Emotion Review, 5:2, 119-124.

Roseman, I. J. \& Smith, C. A. (2001). Appraisal Theory: Overview, Assumptions, Varieties, Controversies. In: Scherer, K. R., Schorr, A. \& Johnstone, T. (eds.) Appraisal Processes in Emotion: Theory, Methods, Research. New York: Oxford University Press.

Smith, C. A. \& Kirby, L. D. (2001). Toward delivering on the promise of appraisal theory. In: Scherer, K. R., Schorr, A. \& Johnstone, T. (eds.) Series in affective science. Appraisal processes in emotion: Theory, methods, research. New York: Oxford University Press.

Smith, C. A., Tong, E. M. W. \& Ellsworth, P. C. (2014). The Differentiation of Positive Emotional Experience as Viewed through the Lens of Appraisal Theory. In: Tugade, M. M., Shiota, M. N. \& Kirby, L. D. (eds.) Handbook of Positive Emotions. New York: Guildford Press.

van Leeuwen, T. (2006). Introducing social semiotics, London, Routledge

Williamson, B. (2005). What are multimodality, multisemiotics and multiliteracies? [Online]. Available: http://www. futurelab.org.uk/resources/publications-reports-articles/ web-articles/Web-Article532 [Accessed 2 December 2009]. 